\title{
Aus dem Vorwort zur ersten Auflage
}

Der in den letzten Jahren besonders schnell fortgeschrittenen Entwicklung des Kraftfahrwesens ist die Gesetzgebung mit zahlreichen Anderungen der den Verkehr regelnden Bestimmungen gefolgt. Der Anregung des Herrn Verlegers, eine Neuausgabe der geltenden Vorschriften zu veranstalten, stand zwar das Bedenken entgegen, daß eine Reihe Kommentare bereits vorhanden ist; wenn ich mich gleichwohl entschlossen babe, die Zahl der Erläuterungen zum Kraftfahrzeuggesetz um eine zu vermehren, so waren dafür zwei Umstände maßgebend: Die vorhandenen Werke stammen, von nur mit kurzen Anmerkungen versehenen Textausgaben abgesehen, aus der Zeit vor dem Kriege und sind durch die erwähnten zahlreichen Anderungen der Vorschriften überholt; ferner enthalten sie die für die Regelung des Verkehrs besonders wichtige .Verordnung über Kraftfahrzeugverkehr" teils überhaupt nicht, teils nur in Wiedergabe des Textes, und soweit endlich die Verordnung erläutert ist, halten sich die Anmerkungen in knappstem Rahmen, abgesehen davon, daß sie frühere Fassungen betreffen. Hiernach konnte wohl angenommen werden, daß ein die heut gültigen Bestimmungen zugrundelegender Kommentar, der besonders Gewicht auf ausführliche Erläuterung gerade auch der Verordnung legt, tatsächlich eine Lücke ausfülit . . .

Berlin, im Februar 1926. 